\title{
Meat quality of pork loins from Hereford $\times$ Berkshire female and intact male pigs reared in an alternative production system
}

\author{
Yvette Robbins ${ }^{1}$, Hyeon-Suk Park ${ }^{1}$, Travis Tennant ${ }^{2}$, Dana Hanson ${ }^{3}$, Niki Whitley ${ }^{4}$, \\ Byungrok Min', and Sang-Hyon $\mathrm{Oh}^{5, *}$
}

\footnotetext{
* Corresponding Author: Sang-Hyon Oh Tel: +1-410-651-7572, Fax: +1-410-651-7931 E-mail: shoh@umes.edu

${ }^{1}$ Department of Animal Science, North Carolina Agricultural and Technical State University, Greensboro, NC 27411, USA

2 Department of Agricultural Sciences, West Texas A\&M University, Canyon, TX 79016, USA

${ }^{3}$ Department of Food, Bioprocessing, \& Nutrition Sciences, North Carolina State University, Raleigh, NC 27695, USA

${ }^{4}$ Department of Agricultural Sciences, Fort Valley State University, Fort Valley, GA 31030, USA

${ }^{5}$ Department of Agriculture, Food, and Resource Sciences, University of Maryland Eastern Shore, Princess Ann, MD 21853, USA

a These authors contributed equally to this work.
}

ORCID

Yvette Robbins

https://orcid.org/0000-0003-0940-3941 Hyeon-Suk Park

https://orcid.org/0000-0003-0358-7903

Travis Tennant

https://orcid.org/0000-0002-1298-0099

Dana Hanson

https://orcid.org/0000-0001-5834-6547 Niki Whitley

https://orcid.org/0000-0001-8067-6745

Byungrok Min

https://orcid.org/0000-0003-4108-6579

Sang-Hyon Oh

https://orcid.org/0000-0002-9696-9638

Submitted Sept 6, 2018; Revised Oct 23, 2018; Accepted Jan 10,2019
Objective: The objective of the present study was to investigate pork quality from Hereford $x$ Berkshire female and intact male pigs reared outdoors in an alternative production system. Methods: Berkshire purebred sows were artificially inseminated, once in the fall and again in the spring of the following year, with semen from Hereford boars and managed free of antibiotics in an outdoor hoop structure until the last month of pregnancy, after which they were moved to a pasture-based unit of 0.8 hectares with individual lots with a farrowing hut, shade, and water ad libitum. Piglets were weaned at 4 weeks of age and housed in a deepbedded hoop structure, grouped by sex. Animals were harvested at market weight of $125 \mathrm{~kg}$, approximately 200 days of age. Hot carcass weight was collected at the time of the harvest. After 24 hours of refrigeration, carcass characteristics were measured. Longissimus dorsi samples collected from the right side loin. Loins were cut into $2.54-\mathrm{cm}$ thick chops and were used to measure marbling score, color score, drip loss, and ultimate $\mathrm{pH}$. Sensory panel tests were conducted as well at North Carolina State University. For pork characteristics and sensory panel data, trial and sex were included in the statistical model as fixed effects. Hot carcass weight was included in the model as a covariate for backfat thickness.

Results: Neither the subjective nor the objective color scores displayed any differences between the boars and the gilts. No difference was found for $\mathrm{pH}$ and marbling score between trials or sexes. Gilts had a thicker backfat measurement at the last lumbar and a narrower longissimus muscle area measurement when compared to the boars. The only difference in the sensory characteristics was found between the trials for texture and moisture scores. Conclusion: Consumers were not able to detect boar taint under the condition of this study, which is that the intact males were reared outdoors. Additional trials would be necessary; however, based on the results of the present study, outdoor rearing can be suggested as a solution to the issue of boar taint.

Keywords: Pork Quality; Boar Taint; Outdoor Production; Sex

\section{INTRODUCTION}

Modern day definition of meat quality has evolved from an objective assessment obtained through quantitative performance tests to include a subject assessment shaped by nonquantitative factors, such as rearing condition, use of antibiotics or unnatural surgical procedures, and etc., in response to the growing consumer concerns about animal welfare, which have led to a higher preference for products from organically raised animals. Among modern day consumers, a perceived gap exists between the conventional and organic pig production methods [1]. Generally, consumers view pigs raised in organic production systems as happy and naturally raised, without growth promoters, given larger spaces and allowed to exercise natural behaviors. Conversely, consumers view pigs raised in conventional systems 
as unhappy, unable to roam freely as they would in nature, and unnaturally grown at a faster rate. Consumers also associate production method with pork quality [2]. When products were labeled "organic" or "free range", consumers applied positive attributes, such as better animal welfare and tastiness, to the products [3]. Furthermore, when information about the process characteristics of the product was provided, consumers were willing to pay premium for the products labeled organic or natural [4].

In response to growing concerns of consumers, production systems in which animals are naturally or organically raised have grown in popularity among producers. One of the characteristics that define an organic farming system is the absence of surgical procedures, such as the castration of the boars. Though the absence of castration appeals to the consumers for its consideration of animal welfare, it is known to depreciate the product value due to the negative eating quality associated with the meat. The negative eating quality, namely the foul smell in the cooked meat referred to as boar taint, is caused by three main biochemical compounds: Androstenone, skatole, and indole [5,6]. Breed difference in boar taint score, based on the amount of the three main biochemical compounds in the meat, have been identified by a number of studies [7-9], and heritability of the boar taint compounds makes it possible to selectively breed against them [10]. Furthermore, evidence suggests there is no difference in the eating qualities of gilts and uncastrated boars when the animals are reared outdoors [11,12]. Therefore, the objective of the present study was to investigate the eating quality of pork from Hereford $\times$ Berkshire (HB) female and intact male pigs reared outdoors in an alternative production system. It was hypothesized that there would not be any difference in meat qualities between uncastrated male pigs and female pigs. The system was not labeled organic due to the lack of certification of the facility; however, the rearing environment was kept as close to a rearing environment at a certified organic production facility as possible.

\section{MATERIALS AND METHODS}

\section{Animals}

The experiment was conducted at NC A\&T State University, located in Greensboro, NC, USA (IACUC: 12-003.0). Two trials were conducted, once in the fall of 2015 and once in the spring of 2016. The sows used for breeding were Berkshire purebreds artificially inseminated with semen from Hereford boars and managed free of antibiotics in an outdoor hoop structure until the last month of pregnancy, after which they were moved to a pasture-based unit of 0.8 hectares with individual lots $\left(14 \times 24 \mathrm{~m}^{2}\right)$ with a farrowing hut, shade, and water ad libitum. Piglets were weaned at 4 weeks of age and housed in a deep-bedded hoop structure, grouped by sex. In the first trial, there were 8 females and 13 intact males. In the second trial, there were 5 females and 5 intact males. The piglets were given access to standard National Research Council balanced rations and water ad libitum. Variables measured are listed in Table 1.

\section{Carcass data collection}

In the first trial, 6 Berkshire sows sired by Hereford farrowed $21 \mathrm{HB}$ pigs. In the second trial, 3 sows farrowed $10 \mathrm{HB}$ pigs. All of the females from the first and the second trials were used to collect carcass data. Of the 13 intact males in the first trial, 8 were randomly selected to match the number of females in the first trial. All of the intact males in the second trial were used. Animals were harvested at a USDA-inspected abattoir at market weight of $125 \mathrm{~kg}$ and approximately 200 days of age. Carcass collection procedures followed the guidelines set by National Pork Producers Council [13]. Hot carcass weight, including the head, was collected at the time of the harvest. After 24 hours of refrigeration at $4^{\circ} \mathrm{C}$, carcass characteristics, such as the backfat depths at the 1st rib, 10th rib and last lumbar, as well as the longissimus muscle area (LMA), were measured. The longissimus dorsi (LD), collected from the right side loins, was packed and transported to the NCSU Processed Meat Laboratory, approximately an hour away from the abattoir, for storage at $2^{\circ} \mathrm{C}$ until further analysis.

\section{Pork quality measurements}

The LD samples collected from the right side loins were cut into 2.54-cm thick chops and were used to measure the marbling score (1 to 10) and the color score (1 to 6). One hundred gram samples trimmed from each LD were placed on hooks

Table 1. Least square means and standard errors of each characteristic by trial and sex for pigs raised in alternative production system

\begin{tabular}{|c|c|c|c|c|}
\hline \multirow{2}{*}{$\begin{array}{l}\text { Variables } \\
\text { measured }\end{array}$} & \multicolumn{2}{|c|}{ Trial } & \multicolumn{2}{|c|}{ Sex } \\
\hline & 1 & 2 & Boar & Gilt \\
\hline pH & $5.76 \pm 0.02$ & $5.73 \pm 0.03$ & $5.76 \pm 0.03$ & $5.73 \pm 0.03$ \\
\hline Color score & $3.44 \pm 0.19$ & $3.20 \pm 0.24$ & $3.59 \pm 0.22$ & $3.05 \pm 0.22$ \\
\hline$L^{*}$ & $53.2 \pm 0.92$ & $54.5 \pm 1.16$ & $53.4 \pm 1.03$ & $54.3 \pm 1.03$ \\
\hline$a^{*}$ & $9.19 \pm 0.44$ & $8.04 \pm 0.56$ & $9.18 \pm 0.50$ & $8.05 \pm 0.50$ \\
\hline$b^{*}$ & $6.03 \pm 0.44^{a}$ & $4.32 \pm 0.56^{b}$ & $5.40 \pm 0.50$ & $4.95 \pm 0.50$ \\
\hline Marbling score & $2.31 \pm 0.29$ & $1.60 \pm 0.37$ & $1.76 \pm 0.33$ & $2.15 \pm 0.33$ \\
\hline $\mathrm{BF} 1(\mathrm{~cm})$ & $4.35 \pm 0.22$ & $4.37 \pm 0.29$ & $4.42 \pm 0.25$ & $4.30 \pm 0.24$ \\
\hline $\mathrm{BF} 10(\mathrm{~cm})$ & $1.78 \pm 0.07$ & $1.93 \pm 0.09$ & $1.84 \pm 0.08$ & $1.88 \pm 0.07$ \\
\hline $\mathrm{BFLL}(\mathrm{cm})$ & $2.63 \pm 0.19$ & $2.95 \pm 0.25$ & $2.24 \pm 0.21^{\mathrm{a}}$ & $3.35 \pm 0.20^{b}$ \\
\hline $\operatorname{LMA}\left(\mathrm{cm}^{2}\right)$ & $50.8 \pm 1.68$ & $47.2 \pm 2.20$ & $51.8 \pm 1.84^{\mathrm{a}}$ & $46.3 \pm 1.79^{b}$ \\
\hline Drip loss (\%) & $2.64 \pm 0.29^{a}$ & $1.36 \pm 0.36^{b}$ & $2.15 \pm 0.32$ & $1.85 \pm 0.32$ \\
\hline Slice shear force & $19.0 \pm 0.80^{a}$ & $15.8 \pm 1.01^{b}$ & $17.4 \pm 0.90$ & $17.5 \pm 0.90$ \\
\hline \multicolumn{5}{|c|}{$\begin{array}{l}{ }^{*} \text {, indicates muscle lightness; } a^{*} \text {, a measure of muscle redness; } b^{*} \text {, a measure of } \\
\text { muscle yellowness; BF1, 1st rib backfat; BF10, 10th rib backfat; BFLL, last lumber } \\
\text { backfat; LMA, loin muscle area. } \\
\text { a,b Means with different superscripts among groups within each variables meas- } \\
\text { ured differ at } p<0.05 \text {. }\end{array}$} \\
\hline
\end{tabular}


and hung in a plastic bag at $2^{\circ} \mathrm{C}$ for $24 \mathrm{~h}$ to measure drip loss. The ultimate $\mathrm{pH}$ was determined by homogenizing a sample with a variable speed laboratory blender (Waring, New Hartford, CT, USA) and adding deionized water to dilute the sample at a 1:10 ratio. An Accumet Excel XL15 pH meter with glass tip probe (Thermo Fisher Scientific, Waltham, MA, USA) was used to determine the $\mathrm{pH}$ after blending the samples for $20 \mathrm{~s}$. Objective color score Commission Internationale de l'Eclairage (CIE) $\mathrm{L}^{*}$ (lightness), $\mathrm{a}^{*}$ (redness), and $\mathrm{b}^{*}$ (yellowness) was measured using a Minolta Chroma Meter (CR-200, Ramsey, NJ, USA). Using the D65 illuminant and $2^{\circ}$ standard observer, which was calibrated with a standard white plate before each use, the color values were measured at three different positions on the surface of each chop and were averaged.

Slice shear force was conducted to estimate tenderness [14]. The frozen steaks were cut to $2.54 \mathrm{~cm}$ thick and weighed then thawed at $6^{\circ} \mathrm{C}$ for $24 \mathrm{~h}$. Thawed steaks were weighed, and thawed temperature was measured. Steaks were cooked on a conveyorized impingement grill (1100 Series Impinger II Conveyorized Oven, Lincoln Foodservice, Cleveland, $\mathrm{OH}$, USA). With the impingement grill operating at top heat = $210^{\circ} \mathrm{C}$, bottom heat $=210^{\circ} \mathrm{C}$ steaks were cooked for approximately $12.5 \mathrm{~min}$ until an internal temperature of $70^{\circ} \mathrm{C}$. After the steaks exited the belt grill, a needle thermocouple probe was inserted into the geometric center of the steak and postcooking temperature rise was monitored with a hand-held thermometer (Fisher Scientific, Hampton, NH, USA). Cooked steaks were weighed. Steaks were sampled and slice shear force was measured as described by Shackelford et al [15] using a universal testing system (Instron model 5565, Canton, MA, USA).

\section{Sensory panel tests}

Sensory panel tests were conducted at North Carolina State University (Raleigh, NC, USA). The first sensory panel test, which used the pork from Trial 1, had 110 consumer participants and the second test, which used the pork from Trial 2, had 101 consumer participants. The majority of the participants in both Trials, recruited through a screener launched to an on-line database maintained by the Sensory Service Center with over 3,000 members, were between the ages of 29 and 35 (Table 2). Subjects over the age of 18 and under 60 were recruited for this panel. At the end of each experiment, the participants were awarded a five-dollar grocery store gift card.

Upon arrival, the participants filled out an information sheet, answering questions related to their demographics and pork consumption characteristics. Then, the participants were given one sample at a time and were asked to indicate the overall liking as well as overall flavor, freshness and texture likings of the sample on a 9-point Hedonic scale for which 1 $=$ dislike extremely and $9=$ like extremely. Then the partici- pants scored the texture and the moisture of the samples on a just about right (JAR) scale, where 1 or $2=$ too little, $3=J A R$, and 4 or $5=$ too much. Lastly, the participants indicated their purchase intent of the sample on a 5-point scale for which 1 or 2 = probably would not buy, 3 = maybe would or maybe would not buy, and 4 or $5=$ probably would buy. The samples were prepared by thawing the $\mathrm{LD}$ at $4^{\circ} \mathrm{C}$ and cooking at $200^{\circ} \mathrm{C}$ on an Impinger conveyor oven. The cooked samples were wrapped, labeled, and kept warm at $75^{\circ} \mathrm{C}$ inside a warming cabinet. Before serving, the samples were cut into $2 \times 2 \times 1$ $\mathrm{cm}^{3}$ cubes.

\section{Data analyses}

For pork characteristics and sensory panel data, trial and sex were included in the statistical model as fixed effects using PROC general linear model in SAS 9.3. The interaction between trial and sex was excluded because it was not significant ( $p>0.05$ ). Hot carcass weight was included in the model as a covariate for backfat thickness.

\section{RESULTS AND DISCUSSION}

Presented in Table 1 are the least square means and standard errors of the meat quality traits by trials and sex. Pork from pigs in Trial 1 was significantly more yellow than the pork from pigs in Trial $2(\mathrm{p}<0.05)$. Also, pork from pigs in Trial 1 had significantly higher values for the drip loss and the slice shear force $(\mathrm{p}<0.05)$. Neither the subjective nor the objective $\mathrm{CIE} \mathrm{L}^{*}, \mathrm{a}^{*}$, and $\mathrm{b}^{*}$ color scores displayed any differences between the boars and the gilts ( $p>0.05)$. No difference was found for $\mathrm{pH}$ and marbling score between trials or sexes. As would be expected, gilts had a thicker backfat measurement at the last lumbar and a narrower LMA measurement when compared to the boars $(\mathrm{p}<0.05)$. The only difference in the sensory characteristics was found between the trials for texture and moisture JAR scores (Table 3). Pork from pigs in Trial 1 scored significantly higher in both the texture and moisture JAR Scores $(\mathrm{p}<0.05)$.

\section{Carcass and meat quality}

In general, lean pork is preferred over fatty pork. When consumers from 23 different countries were presented with pork chops of varying fat contents, all but two countries, namely Korea and Japan, showed preference for lean meat, while no country showed a strong preference for the fatty meat [16]. Present study found significant difference in backfat and LMA measurements between gilts and uncastrated boars. The thinner backfat and larger LMA of the boars indicate leaner meat. These findings are consistent with those of the meta-analysis of the sex effect on pork quality performed by Trefan et al [17]. When intact/entire (uncastrated) males (EM), surgically castrated males $(\mathrm{CM})$ and gilts $(\mathrm{G})$ were compared, EM 
Table 2. Demographic information and consumer consumption characteristics for sensory tests on pork chops from pigs raised in an outdoor hoop barn

\begin{tabular}{|c|c|c|c|}
\hline Consumer consumption characteristics & Demographic information & Trial $1(n=110 ; \%)$ & Trial $2(n=101 ; \%)$ \\
\hline \multirow[t]{2}{*}{ Gender } & Male & 45.0 & 49.5 \\
\hline & Female & 65.0 & 50.5 \\
\hline \multirow[t]{8}{*}{ Age } & 18 years old or younger & 0.0 & 0.0 \\
\hline & 19-24 years old & 12.7 & 26.7 \\
\hline & $25-35$ years old & 38.2 & 36.6 \\
\hline & $36-45$ years old & 14.5 & 8.9 \\
\hline & $46-55$ years old & 17.3 & 16.9 \\
\hline & $56-65$ years old & 15.5 & 10.9 \\
\hline & $66-70$ years old & 0.9 & 0.0 \\
\hline & 71 years old and over & 0.9 & 0.0 \\
\hline \multirow[t]{2}{*}{ Primary shopper } & Yes & 93.6 & 88.1 \\
\hline & No & 6.4 & 11.9 \\
\hline \multirow[t]{9}{*}{ Purchased and consumed } & Today & 2.7 & 2.0 \\
\hline & At least once within the last week & 26.4 & 30.7 \\
\hline & At least once within the last two weeks & 23.6 & 24.8 \\
\hline & At least once within the last month & 23.6 & 15.8 \\
\hline & At least once within the last 2 months & 8.2 & 7.9 \\
\hline & At least once within the last 3 months & 3.6 & 9.9 \\
\hline & At least once within the last 6 months & 8.2 & 5.9 \\
\hline & At least once within the last year & 0.9 & 3.0 \\
\hline & I do not purchase pork chops & 2.8 & 0.0 \\
\hline \multirow[t]{2}{*}{ Future purchase and consume } & Yes & 99.1 & 100.0 \\
\hline & No & 0.9 & 0.0 \\
\hline \multirow[t]{9}{*}{ Income } & $<\$ 19,999$ per year & 8.2 & 12.9 \\
\hline & $\$ 20,000-\$ 29,999$ per year & 5.5 & 12.9 \\
\hline & $\$ 30,000-\$ 39,999$ per year & 15.5 & 5.9 \\
\hline & $\$ 40,000-\$ 49,999$ per year & 16.4 & 17.8 \\
\hline & $\$ 50,000-\$ 59,999$ per year & 8.2 & 12.9 \\
\hline & $\$ 60,000-\$ 69,999$ per year & 12.7 & 8.9 \\
\hline & $\$ 70,000-\$ 79,999$ per year & 7.3 & 7.9 \\
\hline & $\$ 80,000-\$ 89,999$ per year & 10.0 & 5.0 \\
\hline & Greater than $\$ 90,000$ per year & 16.2 & 15.8 \\
\hline
\end{tabular}

* Percentage of consumers that selected these options is presented and provides a sum total of $100 \%$ for each category.

Table 3. Least square means and standard errors of sensory traits evaluating meat from Berkshire crossbreds sired by Hereford boars

\begin{tabular}{lcclcc}
\hline \multirow{2}{*}{ Sensory traits } & \multicolumn{2}{c}{ Trial } & & \multicolumn{2}{c}{ Sex } \\
\cline { 2 - 3 } \cline { 5 - 6 } & $\mathbf{1}$ & $\mathbf{2}$ & & Male & Female \\
\hline Overall liking $^{1)}$ & $5.77 \pm 0.12$ & $5.97 \pm 0.12$ & & $6.01 \pm 0.12$ & $5.73 \pm 0.12$ \\
Overall flavor liking $^{1)}$ & $5.87 \pm 0.11$ & $5.93 \pm 0.12$ & & $5.99 \pm 0.12$ & $5.82 \pm 0.12$ \\
Freshness liking $^{1)}$ & $6.17 \pm 0.10$ & $6.20 \pm 0.11$ & & $6.28 \pm 0.10$ & $6.09 \pm 0.10$ \\
Texture liking $^{1)}$ & $5.38 \pm 0.13$ & $5.71 \pm 0.14$ & & $5.66 \pm 0.14$ & $5.43 \pm 0.14$ \\
Texture JAR $^{2)}$ & $3.64 \pm 0.05^{\mathrm{a}}$ & $3.50 \pm 0.05^{\mathrm{b}}$ & & $3.56 \pm 0.05$ & $3.57 \pm 0.05$ \\
Moisture JAR $^{2)}$ & $2.56 \pm 0.04^{\mathrm{a}}$ & $2.75 \pm 0.04^{\mathrm{b}}$ & & $2.71 \pm 0.04$ & $2.60 \pm 0.04$ \\
Purchase intent $^{3)}$ & $2.94 \pm 0.08$ & $3.00 \pm 0.09$ & & $3.06 \pm 0.08$ & $2.86 \pm 0.08$ \\
\hline
\end{tabular}

\footnotetext{
1) Liking attributes are scored on a 9-point hedonic scale where $1=$ dislike extremely and 9 = like extremely.

2) Just about right (JAR) scales are scored on a 5-point scale where too little $=1$ or $2, \mathrm{JAR}=3$ and too much $=4$ or 5 .

3) Purchase intent questions were scored on a 5 pt scale where 1 or 2 = probably would not buy, $3=$ maybe would or maybe would not buy, and 4 or $5=$ probably would buy.

$a, b$ Least square means with different superscripts differ $(p<0.05)$.
}

had the thinnest backfat measurement and the smallest intramuscular fat (IMF) percentage. Similar findings were reported by Grela et al [18]. When the EM, CM, and G of the Polish native Pulawska breed reared outdoors were compared. The EM had the thinnest backfat at the midback and the shoulder. Though the difference in LMA between EM and G were not significant, EM had slightly narrower LMA. Compared to the LMA of the CM, LMA of EM were significantly wider $(\mathrm{p}<0.05)$.

\section{Selective breeding as an alternative to surgical castration}

Consumer preference for lean pork makes boar meat profitable, if boar taint weren't an issue. For centuries, farmers have surgically castrated the male pigs as a way of preventing boar taint. However, growing consumer interest in animal welfare is bringing an end to the practice. In 2010, stakeholders from 
the European pig production industry voluntarily signed the 'Brussels Declaration' to eliminate the surgical castration of pigs without anesthesia or analgesia by 2012 and phase out surgical castration completely by 2018 . These goals have not been met, however, due to the lack of a sufficient alternative method to prevent boar taint [19].

Currently, there are three major alternatives to surgical castration: immunocastration, genomic selection and breeding. Immunocastration is vaccination against gonadotropinreleasing hormone (GnRH). Vaccination against GnRH helps prevent boar taint by reducing the concentrations of testicular steroids, including androstenone and skatole [20]. Adaptation of immunocastration among farmers is low. Farmers showed concerns for consumer acceptability of the vaccination and were reluctant to readily apply immunocastration, referring to possible meat safety risks during consumption [21]. The notion of meat safety concerns was shared by the consumers as well. Given brief descriptions of immunocastration, consumers showed low acceptance of meat from immunocastrated animals [22]. Application of immunocastration in place of surgical castration seems unlikely unless consumer concerns regarding residues from the vaccination is resolved [23].

Genomic selection and breeding against boar taint are based on the idea of genetic modification that has long been practiced since the first domestication of livestock. Wild animals were domesticated by selectively breeding animals with high docility. Then, domesticated animals with favorable qualities, such as large litter size and faster growth, were selectively bred, resulting in genetically modified farm animals with high economic values. Recent advancements in technology have allowed for more accurate selection based on genetic data. The moderate-high heritability of the biochemical compounds responsible for boar taint makes genetic selection against boar taint based on these compounds possible [10]. While genomic selection may represent a long-term solution to the issue [24], extensive field applications in commercial pig population may be limited by the economic aspects associated with genomic selection. According to Samore, the price of genotyping, along with the increased expenses in additional infrastructure associated with genotyping, is too high compared to the value of the individual animals [25].

According to Backus et al [26], significant genetic variations of androstenone and skatole indicate heritable differences between breeds and families within breeds, and studies have found breed differences in the levels of boar taint compounds. When Belgian Landrace (BL), Large White (LW) and Pietrain (P) breeds were compared, $\mathrm{P}$ had the lowest levels of Skatole all throughout the varying slaughter weights $(\mathrm{p}<0.01)$, and the levels of androstenone were generally lower for both $\mathrm{BL}$ and P compared to LW except at the $90 \mathrm{~kg}$ slaughter weight $(p<0.05)$ [8]. When levels of Skatole were compared between
Yorkshire, Landrace, Hampshire and Duroc pigs, Duroc had the highest level with a left skewed frequency distribution of plasma skatole concentrations [27]. The breed differences in the levels of boar taint compounds suggest it is possible to selectively breed pigs that do not have boar taint. Babol et al [27] suggests that rearing environments may largely influence the variations in the levels of boar taint compounds. Present study found an elimination of boar taint in pork from organically reared $\mathrm{HB}$ crossbreds. This study is the first to evaluate the sensory characteristics of organically reared HB crossbreds, and thus direct comparisons are not feasible. However, a number of other studies have also related rearing conditions with the amount of boar taint compounds in the meat. van Wagenberg et al [28] found an association between smaller group size and lower farm-level boar taint prevalence. Along with findings by Giersing et al [29], which showed that the aggressive behavior of boars is associated with the level of androstenone in the pigs, the association between smaller group size and lower farm-level boar taint prevalence helps explain the elimination of boar taint found in the present study. According to Cornale et al [30], pigs housed in low stocking density with environmental enrichment show less aggressive behavior. This suggests that rearing pigs organically, in low stocking density with access to straw bedding or other forms of enrichment, reduces the aggressive behavior of boars and thus reduces the chance of tainted meat.

\section{CONCLUSION}

In these Berkshire crossbreds pigs sired by Hereford boars reared outdoors, the gilts had thicker backfat measurements at the last lumbar but narrower loin muscle areas $(\mathrm{p}<0.05)$. However, no difference in the IMF content, or marbling, was observed $(\mathrm{p}>0.05)$. Furthermore, no difference in the eating quality of pork was observed between the sexes ( $p>0.05)$. Consumers were not able to detect boar taint in these intact males reared outdoors and slaughtered at market weight. However, based on this and other studies, the effects of sex seem to differ with the breed studied. Additional trials would be necessary; however, based on the results of the present study, outdoor rearing can be suggested as a solution to the issue of boar taint.

\section{CONFLICT OF INTEREST}

We certify that there is no conflict of interest with any financial organization regarding the material discussed in the manuscript.

\section{ACKNOWLEDGMENTS}

The authors are grateful for supporting research titled in "Outdoor Swine Production Management" by the USDA National 
Institute of Food and Agriculture, Hatch project number NC.X282-5-14-120-1.

\section{REFERENCES}

1. Migliore G, Schifani G, Cembalo L. Opening the black box of food quality in the short supply chain: Effects of conventions of quality on consumer choice. Food Qual Prefer 2015;39:1416. https://doi.org/10.1016/j.foodqual.2014.07.006

2. Caraccioloa F, Ciciaa G, Del Giudice T, et al. Human values and preferences for cleaner livestock production. J Clean Prod 2016;112:121-30. https://doi.org/10.1016/j.jclepro.2015.06.045

3. Heerwagen LR, Mørkbak MR, Denver S, Sandøe P, Christensen $\mathrm{T}$. The role of quality labels in market-driven animal welfare. J Agric Environ Ethics 2015;28:67-84. https://doi.org/10.1007/ s10806-014-9521-Z

4. Thorslunda CAH, Sandøea P, Aaslyng MD, Lassen J. A good taste in the meat, a good taste in the mouth - Animal welfare as an aspect of pork quality in three European countries. Livest Sci 2016;193:58-65. https://doi.org/10.1016/j.livsci.2016.09.007

5. Zamaratskaia G, Lou Y, Peacock J, et al. Effect of polymorphism in the porcine cytochrome b5 (CYB5A) gene on androstenone and skatole concentrations and sexual development in Swedish pig populations. Animal 2008;2:190-6. https:// doi.org/10.1017/S1751731107001103

6. Moss BW, Hawe SM, Walker N. Sensory thresholds for skatole and indole. In: M. Bonneau, editor. Measurement and prevention of boar taint in entire male pigs. Paris, France: INRA; 1993. pp. 63-8.

7. Aluwé M, Millet S, Bekaert KM, et al. Influence of breed and slaughter weight on boar taint prevalence in entire male pigs. Animal 2011;5:1283-9. https://doi.org/10.1017/S175173111 1000164

8. Frieden L, Looft C, Tholen E. Breeding for reduced boar taint. Lohmann Inf 2011;46:21-7.

9. Baes C, Mattei S, Luther H, et al. A performance test for boar taint compounds in live boars. Animal 2013;7:714-20. https:// doi.org/10.1017/S1751731112002273

10. Strathe AB, Velander IH, Mark T, et al. Genetic parameters for androstenone and skatole as indicators of boar taint and their relationship to production and litter size traits in Danish Landrace. J Anim Sci 2013;91:2587-2595. https://doi.org/10. 2527/jas.2012-6107

11.Prunier A, Brillouët A, Merlot E, Meunier-Salaün MC, Tallet C. Influence of housing and season on pubertal development, boar taint compounds and skin lesions of male pigs. Animal 2013;7:2035-2043. https://doi.org/10.1017/S1751731113001596

12. Koucký M, Dostálová A. New trends in market pig production. MASO International BRNO 2011;1:51-5. https:/doi.org/10. 2754/avb201101010051

13. National Pork Producers Council (NPPC). In: Berg EP, editor. Pork composition and quality assessment procedures; Des
Moines, IA, USA; 2000.

14. Shackelford SD, Wheeler TL, Koohmaraie M. Technical note: Use of belt grill cookery and slice shear force for assessment of pork longissimus tenderness. J Anim Sci 2004;82:238-41. https://doi.org/10.2527/2004.821238x

15. Shackelford SD, Wheeler TL, Koohmaraie M. Tenderness classification of beef: II. Design and analysis of a system to measure beef longissimus shear force under commercial processing conditions. J Anim Sci 1999;77:1474-81. https:// doi.org/10.2527/1999.7761474x

16. Ngapo TM, Martin JF, Dransfield E. International preferences for pork appearance: I. Consumer choices. Food Qual Pref 2007;18:26-36. https://doi.org/10.1016/j.foodqual.2005.07.001

17. Trefan L, Doeschl-Wilson A, Rooke JA, Terlouw C, Bünger L. Meta-analysis of effects of gender in combination with carcass weight and breed on pork quality. J Anim Sci 2013;91:148092. https://doi.org/10.2527/jas.2012-5200

18.Grela ER, Kowalczuk-Vasilev E, Klebaniuk R. Performance, pork quality and fatty acid composition of entire males, surgically castrated or immunocastrated males, and female pigs reared under organic system. Pol J Vet Sci 2013;16:107-14. https://doi.org/10.2478/pjvs-2013-0015

19. De Briyne N, Berg C, Blaha T, Temple D. Pig castration: will the EU manage to ban pig castration by 2018? Porcine Health Manag 2016;2:29. https://doi.org/10.1186/s40813-016-0046-X

20. Merks JWM, Hanenberg EHAT, Bloemhof S, Knol EF. Genetic opportunities for pork production without castration. Anim Welf 2009;18:539-44.

21. Mancini MA, Menozzi D, Arfini F. Immunocastration: Economic implications for the pork supply chain and consumer perception. An assessment of existing research. Livest Sci 2017; 203:10-20. https://doi.org/10.1016/j.livsci.2017.06.012

22. Huber-Eicher B, Spring P. Attitudes of Swiss consumers towards meat from entire or immunocastrated boars: A representative survey. Res Vet Sci 2008;85:625-7. https:/doi.org/10.1016/ j.rvsc.2008.03.002

23. Heid A, Hamm U. Consumer attitudes towards alternatives to piglet castration without pain relief in organic farming: qualitative results from Germany. J Agric Environ Ethics 2012; 25:687-706. https://doi.org/10.1007/s10806-011-9350-2

24.Squires EJ, Schenkel FS. Managing boar taint: focus on genetic markers. London Swine Conference 2010; 2010 Mar 31-Apr 1; London, UK.

25. Samorè AB, Fontanesi L. Genomic selection in pigs: state of the art and perspectives. Ital J Anim Sci 2016;15:211-32. https:// doi.org/10.1080/1828051X.2016.1172034

26. Backus GBC, van den Broek E, van der Fels B, et al. Evaluation of producing and marketing entire male pigs. NJAS Wageningen J Life Sci 2016;76:29-41. https://doi.org/10.1016/ j.njas.2015.11.002

27. Babol J, Zamaratskaia G, Juneja RK, Lundström K. The effect of age on distribution of skatole and indole levels in entire male 
pigs in four breeds: Yorkshire, Landrace, Hampshire and Duroc. Meat Sci 2004;67:351-8. https://doi.org/10.1016/j.meatsci.2003. 11.008

28.van Wagenberg CPA, Snoek HM, van der Peet-Schwering CMC, Vermeer HM, Heres L. Farm and management characteristics associated with boar taint. Animal 2013;7:1841-8. https://doi.org/10.1017/S1751731113001328

29. Giersing M, Lundstrom K, Andersson A. Social effects and boar taint: Significance for production of slaughter boars (Sus scrofa). J Anim Sci 2000;78:296-305. https://doi.org/10. 2527/2000.782296x

30.Cornale P, Macchi E, Miretti S. Effects of stocking density and environmental enrichment on behavior and fecal corticosteroid levels of pigs under commercial farm conditions. J Vet Behavior 2015;10:569-76. https://doi.org/10.1016/j.jveb.2015.05.002 